\title{
Missä olemme ja mitä muistamme, kun olemme etänä?
}

\author{
एैy \\ "Kun inhimillisestä tilasta tulee ei-kenenkään maata, \\ se alkaa vähitellen sijaita ei-missään."
}

Paul Virilio: Katoamisen estetiikka

KUN KORONAEPIDEmia ALKOI Suomessa vuoden 2020 maaliskuun puolivälissä, siirryttiin tekemään työtä erilaisille verkkoalustoille. Kuului puheenvuoroja, joiden mukaan emme enää koskaan palaa siihen tapaan tehdä työtä, johon ennen poikkeusaikaa olimme tottuneet.

Jokin on muuttunut suhteessamme työhön, ja se jokin myös muuttaa tapaamme olla suhteessa toisimme, yhteisöihimme ja organisaatioihimme. Huomiomme kiinnittyi ensimmäisenä koronakeväänä hypetyspuheeseen, jossa varsinkin Suomessa olimme nopeita ja tehokkaita ja pystyimme digiloikkaan. Uusi teknologia ja kommunikoinnin tapa näyttäytyivät rajattomien mahdollisuuksien avaajina. Kuten teknologiapuheessa usein, kriittiset sävyt loistivat poissaolollaan.

Missä oikein olemme, kun olemme etätyössä? Mitä etänä oleminen meille tekee ja millaisia suhteita toisiimme luomme? Kun olemme oppineet arvostamaan etäyhteyksien suomaa vapautta ja maantieteellisten rajojen ylittämistä, emme ehkä halua palata täysin entisenlaisiin työtapoihin. Muuttuvatko huomaamattamme tavat olla yhteydessä toisiimme yhteisen oppimisen ja merkityksenannon kannalta?
Joidenkin tutkimusten mukaan pandemia-aikaan etätyötä lisänneet työskentelevät aiempaa itsenäisemmin ja oppivat aiempaa parempia työtapoja useammin kuin ne, jotka ovat pitäneet etätyön määrän ennallaan. Samalla kyynistyminen on uhkaamassa. Etätyötä on tervehditty työntekijän uutena vapautumiskertomuksena, mutta tutkimukset osoittavat, että etätyötä lisänneet kokevat työnsä usein puuduttavana ja työtovereilta ja esimiehiltä saadun tuen riittämättömänä. Vain alle viidennes haluaisi tehdä etätöitä päivittäin, ja viikoittain etänä työskentelisi vastaisuudessa alle puolet. Etätyössä ollaan tuotteliaita, mutta useat työntekijät kokevat olevansa erityksissä ja kaipaavat kollegoitaan. Luottamus kollegoihin ja esimieheen on koetteilla. Ylipitkä etäkokous ei aina ole tehokkain vaihtoehto. (Eurofound 2021; BBC 2020; TTL 2020; Ruohomäki ym. 2020.)

\section{DIALOGI LUO YHTEISEN TILAN}

Miten etä- ja lähioleminen eroavat toisistaan tilallisuuden, muistamisen ja ruumiillisuuden näkökulmista? 


\section{MUistaminen SUUNTAUTUU}

\section{PAITSI MENNEESEEN, MYÖS}

\section{TULEVAAN.}

Etäyhteyksien ajan alussa vuorovaikutusta ohjasi väline ja sitä koskevat eri alustojen logiikat. Ilmeitä oli vaikea lukea, visuaalinen tapahtuminen oli pysähtyneen hidasta tai päällekkäisyyksiä sisältävän nopeaa. Oli vaikea tietää, miten puhumisen ja hiljaisuuden vuorottelua jaettiin.

Nopeasti kävi ilmi, että fyysisessä vuorovaikutuksessa on paljon sanatonta, hiljaista viestintää, jossa vaikutamme toisiimme ja pystymme kehollisen viestinnän kautta antamaan vihjeitä siitä, milloin haluamme puhua ja tulla ääneen ja milloin annamme tilaa toiselle. Kehollisen viestinnän vaikeutuminen etäyhteyksissä pysäytti tajuamaan sen merkityksen eri tavalla kuin aiemmin. Ilmeet, eleet ja niihin liittyvä kehon kieli sekä tavat, joilla koemme yhteyttä toistemme välillä, avautuivat uudella tavalla.

Niin etä- kuin lähidialogi sitoo ihmiset yhteen ja luo väliaikaisesti yhteisen tilan. Tilaan kuuluvat niin fyysinen, henkinen, emotionaalinen kuin ajallinen tila. Etänä siirrytään fyysisestä ja konkreettisesta tilasta toisenlaiseen tilaan, josta ei välttämättä vielä ymmärretä paljoakaan.

Japanilaistutkija Ikujiro Nonaka kumppaneineen (2001) tutki oppimisen, reflektion ja dialogien tiloja innovatiivisina pidetyissä yrityksissä. Isoimpana haasteena ei tutkijoiden mielestä ole niinkään tiedon johtaminen eikä tuottaminen vaan erilaisten tietojen saattaminen dialogiin uuden ymmärryksen synnyttämiseksi ja eriytyneiden näkökulmien ylittämiseksi. Työntekijöiden hiljainen tieto ei useinkaan artikuloidu aloitteiksi asti. Tutkituissa menestyvissä organisaatioissa on luotu tiloja, joissa toiminnan jäsentämisen ja innovaatioiden tuottamisen eri hierarkiatasojen tahot kohtaavat. Kohtaamisen tiloille on japanin kielessä käsite $b a$, joka tarkoittaa paitsi fyysistä tilaa ja läsnäoloa myös kohtaamisessa toteutuvaa mentaalista ja sosiaalista tilaa. Ba-tilassa astutaan yhteiseen merkitysten virtaan.
Etävuorovaikutuksessa yhteinen tila ja merkitykset näyttäytyvät eri tavoin. Yhteinen sovittautuminen, virittyminen tai rytmittyminen ei synny ilman tietoista tekemistä. Etäyhteyksissä joudumme ponnistelemaan sellaisten asioiden kanssa, jotka kehkeytyvät kasvokkaisessa vuorovaikutuksessa kuin itsestään. Muussa tapauksessa kokemus on vaivaannuttava tai väkinäinen, varauksellinen, ja "normaaleille" urille yritetään päästä takaisin mahdollisimman pian.

Toiminnan affektiivinen sävy rakentuu oman ja toisen tilan jatkuvasta seuraamisesta. Sanoilla, eleillä ja katseilla, joilla vaikutetaan vuorovaikutuskumppaniin, vaikutetaan myös omaan sisäiseen tilaan. Sosiaalista kognitiota on useimmiten tarkasteltu yksilön kannalta, eikä kahden tai useamman henkilön vuorovaikutuksesta ymmärretä vielä paljoakaan.

Itsesäätely ja vuorovaikutuksen säätely ovat tiiviisti yhteydessä toisiinsa. Seuraamme ja säätelemme omaa tilaamme samalla kun seuraamme kumppanin sanoja ja tekoja. Puhuja seuraa jatkuvasti kuulijan katsetta, ilmeitä ja eleitä ja suuntaa puheitaan niiden mukaan, esimerkiksi loiventaen tai terävöittäen kannanottojaan. (Peräkylä \& Gronow 2017.) Etäkontaktissa kuulijan seuraaminen vaikeutuu, ja tunteet jäävät piiloon tai niiden jakaminen tulee joko ohueksi tai korostetun voimakkaaksi.

\section{PAIKKA JA MUISTAMINEN}

Tullessamme yhteen fyysiseen paikkaan läsnä ovat kohtaamisten menneisyys, nykyisyys ja tulevaisuus. Abstraktista tilasta tulee paikka, kun siellä ovat toiset: tilassa on toisten läsnä- tai poissaolo. Inhimillinen todellisuus ja merkitykset syntyvät suhteissa ja toisten kanssa. Toinen suhteellistaa ei-tiedetyn ja ei-havaitun. Työyhteisö suhteellistaa päälle kaatuvia työn vaatimuksia.

Etäalustalla emme juuri saa vihjeitä toistemme fyysisestä ympäristöstä. Näemme toisemme kuvaruudulla, tulemme osaksi kuvaruudun kuvitusta. Etäyhteyksissä tehty työ toistuu samanlaisena. Muistaminen ei kiinnity tilaan, ja tapaamiset lipuvat toistensa virrassa. Ellei mitään poikkeuksellista tapahdu, muistiin ei tunnu jäävän mitään. Kuten 
vankilaoloissa käy, yksi päivä voi tuntua loputtoman pitkältä, mutta jälkeenpäin kuukaudet tuntuvat kuluneen yhdessä hujauksessa. Muisti on suhteissa olevana, aistimellisena ja ruumiillisena sidoksissa vuorovaikutukseen ja fyysisiin paikkoihin.

Muistaminen suuntautuu paitsi menneeseen, myös tulevaan. Vailla muistamista ja unohtamista, aikaperspektiivin puristuessa kokoon, ei ole mahdollista orientoitua tulevaisuuteen.

Filosofi Paul Virilion (1994) mukaan asioiden ja merkkien kiihtyvä vilinä tuottaa muistikatkoksia ja erakoitumista, kun subjekti tempautuu aika-avaruudellisen kontekstin ulkopuolelle. Kesto koostuu kestoa vailla olevista hetkistä kuten suora koostuu syvyyttä vailla olevista pisteistä. Kun olemme ei-missään paikassa, muistikuvamme ovat ei-missään, eikä muistijälkiä välttämättä jää. Etätyö on varmasti tuottavaa, kun siirrytään hetkessä ja ilman siirtymisen rituaaleja tapaamisesta toiseen tai tuotetaan läsnäolon vaikutelmia useassa paikassa yhtaikaa. Aikaa tulee lisää, mutta kiireen tuntu lisääntyy.

Muisti rakentaa minut minuna ja meidät meinä. Organisaation muistilla on samankaltainen tehtävä kuin yksilön muistilla: toiminnan suuntaaminen. Vaikka jokaisella yksilöllä on kyky ainutkertaiseen henkilökohtaiseen muistin varantoon, voimme ymmärtää mieleen tulevan henkilökohtaisen muiston osana ryhmän muistia. Kun tapahtumilla on paikka, yksilön ja yhteisön menneisyys jää eloon tietoisesti ja ei-tietoisesti. (Onnismaa 2021.)

Paitsi yksilön, myös työyhteisön ja organisaation muisti voi ohentua paikattomuuden tai merkkien ylituotannon myötä. Unohtaminen voi organisaatiossa olla suorastaan toivottavaa. Kun erilaiset hankkeet alkavat äkillisesti mutta haudataan vähin äänin, liiallinen muistaminen ja asioihin perehtyminen voidaan nähdä taakkana ja joustavuuden esteenä. (Sennett 2006.)

Jollei muistaminen ole etä- ja lähikontakteissa samanlaista, ei samaa ole ehkä ajattelukaan. Ajattelua pidetään yksilöllisenä ja korvien välissä tapahtuvana, mutta se on sekä ruumiillista että ihmisten välistä: "Ajatukset harhailevat ja etsivät ajattelijaa" (Hyyppä 2017). Käsitystä yksilöstä tulisi laajentaa "tuolle puolen", ruumiilliseen, ja toisaalta "tälle puolen", suhteisiin ja ihmisten välille. Emme muista tai ajattele paljoakaan, ellei meitä kutsuta niin tekemään (Guattari 2011; Gergen 2009). Toisia voi kutsua myös etänä, mutta tähän asti olemme tottuneet lähettämään ja vastaanottamaan kutsuja fyysisessä maailmassa.

\section{NÄEN ITSENI SINUN SILMISSÄSI}

Ihmisten väliset merkitykset siirtyvät, todentuvat ja ilmenevät paljolti ei-symbolisessa prosessissa: kasvojen ilmeinä, äänenpainoina, eleinä ja ruumiin liikkeinä. Sanallinen ja sanaton yhteisymmärrys kuuluu päivittäisiin rutiineihin. Ainutkertaisessa kohtaamisessa syntyy todellisuus, joka ei tyhjene sanalliseen kuvaukseen, vaan se koetaan ruumillisesti. Filosofi Maurice Merleau-Ponty (1962) kirjoitti 1940-luvulla: "Aivan kuin toisen henkilön aikomus tulisi minun ruumiiseeni ja minun hänen ruumiiseensa." Sosiaalinen tila ja tilanne tulee sisäiseksi rakenteekseni ja näen itseni sinun silmissäsi. Antiikin filosofi Aristoteles (384-322 eaa.) ihmetteli, kuin nykyistä neurotiedettä tuntien, miksi meitä haukotuttaa nähdessämme toisen haukottelevan, ja miten on mahdollista, että koemme toisen kärsimyksen.

Filosofi Emmanuel Levinasin (1996) mukaan emme voi tietää toisistamme paljoakaan, mutta voimme saada yhteyden ja olemme toisesta vastuussa - halusimme tai emme - kun näemme toisen kasvot. Mutta nähdessämme toisen kasvot ruudulla ja yrittäessämme katsoa toista silmiin, katsommekin ohi. Miten otamme toisesta vastuun, kun näemme toisen kasvot vinosti?

Toisen ihmisen katse aktivoi autonomista hermostoa ja itseen liittyvää kognitiivista prosessointia. Toisen katse vähentää valehtelemista. Etäyhteydessä olemme näköyhteydessä mutta emme katsekontaktissa. Pyrkimys katsekontaktiin luo uuvuttavan kaksoissidoksen: ollaan läsnä toisten kanssa, mutta samanaikaisesti ei olla. Toiset ovat ikään kuin samassa tilassa, koska heidän kasvonsa näkyvät, vaikka osallistujat eivät ole toisilleen läsnä. Etäyhteyksissä voi tulla viiveitä, ja tutkimuksen mukaan jo 1,2 sekunnin viive vastatessa voi luoda vaikutelman epäystävällisyydestä, varautuneisuudesta tai keskittymisen puutteesta (Hietanen 2020; BBC 2020). Suomalaisen hyväksyttävän viiveajan voi tosin kuvitella tätä pidemmäksi. 
Katsomme visuaalista tapahtumista, jossa olemme itse katsomassa itseämme. Ruudulla näemme itsemmekin muiden joukossa, tulemme ylitietoiseksi itsestämme seuratessamme samaan aikaan itseämme ja toisiamme, mikä rasittaa aivoja - verkko on täynnä uratietoisille suunnattuja neuvoja, miten esiintyä etäyhteyksissä edukseen. Ollessamme tietoisia oman kuvamme näkymisestä toisille emme kuitenkaan voi seurata kovinkaan monen samanaikaisia reaktioita omiin vuorovaikutussiirtoihimme. Toisten kasvonilmeiden tulkintayritykset vievät paljon energiaa. Tai emme näe ihmistä vaan palloja. Puhumme ja vuorovaikutamme ihmisten kanssa, joita emme näe emmekä ehkä juurikaan saa palautetta siitä, millaisia vaikutuksia vuorovaikutussiirroillamme on. (Morris 2020.)

On tärkeää tulla nähdyksi mutta myös olla tulematta nähdyksi. Tietoisuus kamerasta luo tunteen tarkkailtavana olosta. Etäkontaktissa kuvan kytkeminen ajoittain pois voi parantaa kytkeytymistä, kun kuuntelulle ja ajattelulle jää enemmän tilaa.

\section{TURVATON KULJESKELIJA TURVALLISILLA KAUPPAKUJILLA}

Kun jokin meissä on jäänyt irralleen inhimillisestä yhteydestä tulematta yhteisesti jaettavaksi, syntyy paikattomuuden kokemus. Kodittomuudesta ja jalansijattomuudesta kirjoitti sata vuotta sitten omalla tavallaan Walter Benjamin (1892-1940). Hän kuvasi suurkaupunkien kimaltavia ostosgallerioita ja uudenlaista ihmistyyppiä, kuljeskelijaa eli flanööriä. Sanan flâneur teki aiemmin tunnetuksi runoilija Charles Baudelaire.

Flaneeraus tekee inhimillisestä todellisuudesta sarjan irrallisia episodeja. Kohtaamisista tulee sarja ei-kohtaamisia ei-missään tilassa ja vailla muistia. Ostosgalleriat tekevät maailmasta kuljeskelun kannalta turvallisen, ne ikään kuin luovat tai korvaavat tarvittavan tilan. Sosiologi Zygmunt Baumanin (1996) sanoin nämä oudot galleriat ja peilisalit [lue tässä: nettimaailmat]:

"[o]vat maailmoja, jotka suunnittelijat ovat tehneet mittatilaustyönä kuljeskelijalle. Ne ovat eikohtaamisten, taatusti lyhytkestoisten ja ohimenevien tapaamisten näyttämöitä, irrallaan menneestä ja tulevasta, kimaltelevaa pintaa. Niissä jokainen kuljeskelija voi kuvitella olevansa ohjaaja, vaikka tosiasiassa kaikki kuljeskelijat ovat täällä ohjattavia [--] kun houkutellaan, tuntuu kuin haluaisi itse; kun painostetaan, tuntuu kuin aikoisi itse. Ostosgallerioissa - elämässä kuljeskelevana ostajana ja ostavana kuljeskelijana - riippuvuus hajoaa vapaudeksi ja vapaus etsii riippuvuutta.”

Baumanin mukaan nykyiset elämäntavat vapauttavat ihmisen monista kahleista, mutta kytkevät hänet irti myös moraalisista tunteista. Vaihdettavissa suhteissa ja yhteisöissä sitoudutaan, kunnes toisin ilmoitetaan. "Notkeat" yhteisöt, joita on toki muuallakin kuin verkossa, ovat ikään kuin naulakoita, joissa oma takki pysyy vain hetken ennen kuin siirtyy taas uuteen naulakkoon. Verkko ei ole luonut yksilöllistymistä, naulakkoyhteisöllisyyttä tai notkeaa kevytkohtaamista, mutta verkkovuorovaikutus tuntuu soveltuvan hyvin tällaiseen olemisen tapaan.

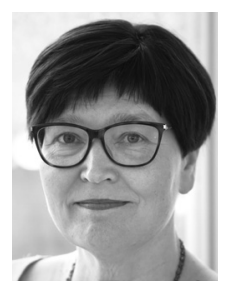

\section{TUULA KIANDER}

KM, työnohjaaja

STO ry

organisaatiokonsultti

FINOD, Werka kehitys Oy

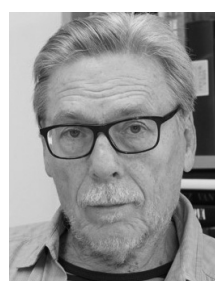

JUSSI ONNISMAA

FT, dosentti, tietokirjailija, työnohjaajakouluttaja 


\section{LÄHTEET}

Bauman, Z. (1996). From pilgrim to tourist, or a short history of identity. Teoksessa S. Hall \& P. du Gay (toim.) Questions of Cultural Identity. Bauman-sitaatin suomentanut M. Perlinen. London: Sage, 18-36.

BBC Worklife (2020). The reason Zoom calls drain your energy - BBC Worklife

Eurofound (2021). Living, working and COVID-19 (Update April 2021): Mental health and trust decline across EU as pandemic enters another year. Layout 1 (europa.eu).

Gergen, K. (2009). Relational Being: Beyond self and community. Oxford: Oxford Univ Press.

Guattari, F. (2010/1992). Kaaosmoosi. Helsinki: Tutkijaliitto.

Hyyppä, H. (2017). Kolme kirjoitusta kokemuksesta. Oulu: Rajantaju/Organisaatiodynamiikan instituutti OD1.

Hietanen, J. (2020). All eyes on eye contact: Studies on cognitive, affective, and behavioral effects of eye contact. Tampere Univ Diss 316. Sartre-lainauksen suomentanut J. Hietanen.

Levinas, E. (1996/1982). Etiikka ja äärettömyys. Helsinki: Gaudeamus.

Merleau-Ponty, M. (1962/1945). Phenomenology of Perception. London: Routledge.

Morris, B. (2020). Why Does Zoom Exhaust You? Science Has an Answer - WSJ Wall St Journal 27.5.2020.
Nonaka, I., Konno, N. \& Toyama, R. (2001). Emergency of "Ba": A conceptual framework for the continuous and self-ascending process of knowledge creation. Teoksessa I. Nonaka \& T. Nishiguchi (toim.) Knowledge Emergency: Social, technical, and evolutionary dimensions of knowledge creation. Oxford: Oxford Univ Press, 13-29.

Onnismaa, J. (2021). Organisaation aika, muisti ja etiikka. Helsinki: Basam Books.

Peräkylä, A. \& Gronow, A. (2017). Ihmismieli ja sosiaalinen vuorovaikutus. Teoksessa A. Gronow \& T. Kaidesoja (toim). Ihmismielen sosiaalisuus. Helsinki: Gaudeamus, 54-75.

Ruohomäki, V., Tuomivaara, S., Mattila-Holappa, P., Monni T.-M., Perttula, P., Alanko, T. ja Toppinen-Tanner, S. (2020). Etätyö koronaepidemian hallitsemisessa sekä vaikutukset työhyvinvointiin ja töiden sujumiseen. Psykologia 55(5), 388-395.

Sennett, R. (2006). The culture of the new capitalism. New Haven: Yale Univ Press.

TTL (2020). Suomalaisten työhyvinvointi kääntyi laskuun koronan pitkittyessä. Työterveyslaitos.

Virilio, P. (1994). Katoamisen estetiikka. Helsinki: Gaudeamus. 